\title{
GUEST EDITORIAL Women and Sustainable Development, A Reflection
}

\author{
Bobbi S. Low \\ Mita Sengupta \\ University of Michigan
}

\begin{abstract}
As we approach the turn of the century, two problems seem to converge repeatedly, in academic and philosophical discourse, and in the media: resource consumption and population growth. Resource degradation and resource inequities are widely recognized and debated. At the Rio conference in 1992, quite public accusations of profligate consumption and reckless reproduction flew back and forth among "Northern" (developed) and "Southern" (developing) nations.

Today, there is increasing emphasis among researchers, policy makers and the popular media on the critical roles women play in fertility decisions, family health and the management of natural resources. How can we make effective use of our information? In this special issue of Population and Environment, scholars from anthropology, population and international health, psychology, and biology cooperate in an interdisciplinary exploration of the evolutionary roots of these patterns. These papers were originally presented at a Workshop on Women and Sustainable Development, held in December, 1994 at the University of Michigan, sponsored by the Population-Environment Dynamics Project and funded by the United Nations Population Fund (UNFPA), among others.

Several generalizations emerge from this endeavor: [1] Humans, like other primates, appear to have evolved to seek and use resources to en-
\end{abstract}

Please address correspondence to Dr. Low or Mita Sengupta, School of Natural Resources and Environment, University of Michigan, Ann Arbor, MI 48109-1115.

Population and Environment: A Journal of Interdisciplinary Studies

Volume 18, Number 2, November 1996

(C) 1996 Human Sciences Press, Inc. 
hance individual survival and reproduction; and [2] For some simple, but powerful, reasons, males and females have evolved to be quite different in the amounts of resources they seek, and the risks they routinely incur. Yet today men's and women's roles are sometimes similar, sometimes widely divergent. Are there patterns, and can these patterns tell us anything about how to use what we know to promote sustainable development?

Our aim is to integrate what we know separately in several disciplines, and to ask whether this consolidated knowledge can help us in solving the dilemmas. We are all intensely interested in differences between the sexes, from "vive la difference" to Freud's plaintive "what do women want?" to current debates over what, if any, sex differences are real, and which, if any, should count in social decisions. Here we introduce a somewhat different perspective, that of behavioral ecology. This perspective gives us new insight on phenomena that are older and broader than we usually imagine. The question is: Can we use our theoretical and empirical knowledge of male-female differences in resource acquisition to promote sustainable development?

Proposed solutions to consumption-fertility-environmental quality problems seem to fall in a few categories. First, those like Julian Simon (1981) argue that quality of life has consistently improved as the number of people alive has increased. A somewhat related argument, favored by some free-market economists, argues that as nonrenewable resources become scarce, their prices will rise, as will the net benefits to developing alternatives. In contrast, many biologists (e.g., Ehrlich \& Ehrlich, 1990) note that the population growth curve of humans is incomplete: the logistic curves of all other species eventually reach the limits of available resources, the "carrying capacity." The two sorts of scholars are examining the problem at different levels: one in the context of human history and economics, the other more broadly, in terms of the general principles of consumption and population growth.

What do these conflicts mean? It is certainly true that technological changes in agriculture, for example, can increase yields in crops, and raise the carrying capacity at least temporarily. Of course, such solutions may carry other costs (e.g., Ehrlich, Ehrlich, \& Daily, 1993), and biologists doubt that human populations will be an exception to the general rule by growing exponentially, without limit, forever. And the crunch, when it comes, is likely to be unpleasant, at the least, for many. A number of environmentalists, agreeing on predictions of future shortages, propose normative solutions, in contrast to free-market propositions. In a recent New York Times magazine feature, for example, Bill McKibben (1995) proposed "We need bicycles and we need buses, and we need to make them seem as marvelous as Miatas." 
BOBBI S. LOW AND MITA SENGUPTA

The papers here by Low, Hawkes, and Wilson explore the evolutionary relationships among resources, consumption, and fertility; sex differences in these relationships; and how the history of such differences play out in male versus female perception of the environment and resources. Males, who in most species specialize in directing their reproductive effort toward getting mates (attaining status and resources useful to families), tend to spend effort in high-risk, high-gain resource activities; males in many primate species, for example, risk serious wounds in raids on other groups to steal females, and in many mammals the bulk of adult mortality arises from deaths from male-male fights over mating access (reviewed by Low, 1993). Females in species in which they are specialized for post-natal parental care (including mammals), have evolved to be risk-averse, both in terms of avoiding failure and avoiding injury and death, for a female who dies while her offspring are dependent, loses her offspring as well. Thus the ecology of resource acquisition and use, and the effect of resources on survival and fertility, are likely to be different for males and females-in most environments, the two sexes are likely to succeed through use of different strategies. These simple observations have profound implications for sex differences in resource use, as one of us (Low) suggests in the first paper.

People, unlike other primates, regularly consume food acquired by others, and a sexual division of labor is common. At first, one would imagine that marriage would create common economic interests (like the New Yorker cartoon in which a caveman explains "I hunt and she gathers; otherwise we couldn't make ends meet"). But in fact, the "disruptive" selection that creates sex differences also means that males and females literally have different reproductive goals; Kristen Hawkes sets the stage and analyzes these issues in several hunter-gatherer societies. Margo Wilson and co-authors tackle the modern descendant of this dilemma: how do men and women view their economic costs and benefits, in the context of environmental conditions? Though a thoroughly modern problem to solve, and one of interest not only to working men and women but their employers, this issue, as Wilson et al. show, has very old roots in the sex differences in resource ecology.

Patterns we see over evolutionary time result from the action of natural selection and historical particulars, and as societies grow large, the influence of (sometimes large) coalitions of individuals who band together to lobby for their interests. Often we can see how traits came to prevail by looking at comparative samples, or changes over time. But today we live in a world that is quite novel, from an evolutionary point of view. As Low discusses in the first paper, this often means that we may be responding to proximate cues that used to be reliable correlates of success, but that we 
have now unhooked from their evolutionary purpose: it is probably true that making love is more fun than sticking your hand into red-hot coals, because sex enhanced reproduction, and second-degree burns never did. But now sex can be decoupled from fertility. Nonetheless, the existence of the Pill hardly suggests that sex will become less pleasurable! Whatever we know about the past, it is probably to the proximate mechanisms we must turn to solve current problems. That is, in the past, men who garnered excess resources typically used them to gain status and reproductive success (Low; Hawkes), and in many societies even today, there is concern for wealth acquisition that we would all agree is far beyond what "worked" in simple survival (Wilson). But in the past, and in hunter-gatherers today, a super-hunter is likely to have more reproductive success than others.

Today we use "sexiness" in advertising, because it works. If we really can convince ourselves that bikes are sexier than Porsches and Miatas, we might convince ourselves to reduce consumption. In other species, and in natural-fertility human societies, resource degradation is associated with low fertility, and when resources are abundant, they are used by families to increase their success relative to other families-usually through higher fertility. Thus when we seek low fertility by reducing consumption and fertility simultaneously, we are seeking something evolutionarily novel. Can we manipulate what we have evolved to seek?

Rekha Mehra examines women's roles in environmental projects, in the Philippines and in Vietnam. Women's active participation does not ensure women's voice in outcomes, or their abilities to capture the benefits of the project. Some projects are currently under external threats. Mehra delineates participatory research techniques and suggests proximate strategies for increasing women's awareness, participation, and benefits.

Even in traditional societies, women suffer a sharper conflict between the activities that produce resources, such as gathering, and what is required for child care (see Hawkes). Kristi McClamroch, using crossnational data, examines the modern equivalent: what happens to women's fertility in developing countries as conditions change. She finds sharp-and nonoverlapping-influence in women's schooling, and their participation in the work force.

Finally, Jennifer Cornman examines some largely unexplored outcomes of sustainable development, if we can attain it. With lower fertility, the number of people in each generation declines, and the number of generations alive at the same time increases. What will this do for the roles and status of women in developing countries? Cornman examines these questions in Sri Lanka, focusing principally on the role of women as elderly care givers, and on the status of elderly women in this society. 
In bringing together these analyses, we see both that the roles women play are diverse, and that some uniting patterns exist: women seldom engage in high-stakes, risky resource work, and women seldom control either significant resources or resource policy at the national level. The papers in this volume begin to explore the dimension of women's roles in population-environment problems. They offer few answers, but perhaps present a useful platform for continued analysis.

\section{REFERENCES}

Ehrlich, P. R., \& Ehrlich, A. H. (1990). The population explosion. NY: Simon and Schuster. Ehrlich, P. R., Ehrlich, A. H., \& Daily, G. (1993). Food security, population, and environment. Population and Development Review 19(1), 11-32.

Low, Bobbi S. (1993). Ecological demography: A synthetic focus in evolutionary anthropology. Evolutionary Anthropology 1(5), 177-187.

McKibben, W. (1995). Hope, human and wild. Boston: Little, Brown.

Simon, J. L. (1981). The ultimate resource. Princeton, NJ: Princeton University Press. 